\title{
O GREENSTONE BELTDE GOIÁS: ESTUDOS GEOCRONOLÓGICOS
}

\author{
EDISON R. TOMAZZOLI*
}

\begin{abstract}
THE GOIÁS GREENSTONE BELT: GEOCHRONOLOGIC STUDIES. Goiás Velho Group of the Greenstone Belt is represented by an Archean sequence of volcanic and sedimentary rocks. These rocks are incrusted in others of the Granite-Gneiss Complex and the contact between these two units is made through N70W thrust faults. $\mathrm{Rb} / \mathrm{Sr}$ geochronological analysis in gneiss showed isochronic ages of about $2.670 \mathrm{Ma}$. Isochronic $\mathrm{Rb} / \mathrm{Sr}$ ages gotten on Bugre Creek Gneiss show values of $1.900 \mathrm{Ma}$, perhaps related to reactivations ofthe Transamazonic TectonicThermal Event. A dike of metamorphosed basic rock cutting die Granite-Gneiss Complex also show geochronological age of about $1.275 \mathrm{Ma}$ gotten by $\mathrm{K} / \mathrm{Ar}$ analysis on actinolite. This age is probably related to reactivations ofthe Uruaçuano Cycle. Cataclastic gneiss in contact with rocks ofthe Greenstone Belt was analysed by K/Ar method on muscovite and showed ages of $1.470 \mathrm{Ma}$, probably related with reactivationsof theN70W faults which form the lateral boundaries of this unit.
\end{abstract}

Keywords: Greenstone belt, Goiás, geochronology.

\begin{abstract}
RESUMO O Greenstone Belt de Goiás, ou Grupo Goiás Velho, é representado por urna seqüência vulcanossedimentar arqueana, inserida em rochas do Complexo Granito-Gnáissico através de falhas de empurrão $\mathrm{N70W}$. Datações Rb/Sr em gnaisses circundantes revelaram idades isocrônicas em torno de 2.670 Ma. Reativações transamazônicas mostram-se presentes e foram detectadas por meio de datação isocrônica Rb/Sr sobre o gnaisse Córrego Bugre, que apresentou idade de $1.900 \mathrm{Ma}$. Um dique de rocha básica metamorfizada, inserido em rochas do Complexo Granito-Gnáissico, foi datado pelométodo K/Ar sobre anfibólio e confirmou idade mínima transam azônica de $1.840 \mathrm{Ma}$ Datação K/Ar sobreactinolita de rochametavulcânica básica do Greenstone Belt mostrou idade de 1.275 Ma, revelando provável influência do Evento Uruaçuano na região. Gnaisse cataclasado, posicionado na região de contato com o Greenstone Belt de Goiás, foi datado pelo método K/Ar sobre muscovita recristalizada, indicando idade de 1.470 Ma, relacionado àreativação das falhas de empurrão N70W que limitam lateralmente a faixa.
\end{abstract}

Palavras-chaves: Greenstone belt, Goiás, geocronologia.

INTRODUCÃO Este trabalho analisa os resultados de datações radiométricas pelos métodos $\mathrm{K} / \mathrm{Ar}$ e $\mathrm{Rb} / \mathrm{Sr}$, obtidos a partir de rochas granito-gnáissicas, metavulcânicas, que ocorrem nos arredores da cidade de Goiás (GO), cuja localização e acesso são mostrados na figura Ia.

As datações foram realizadas no Centro de Pesquisas Geocronológicas da Universidade de São Paulo (USP).

Os teores de $\mathrm{Rb}$ e $\mathrm{Sr}$ foram inicialmente obtidos por fluorescência de raios X. A partir deles foi possível efetuar uma seleção de 14 amostras mais favoráveis à datação $\mathrm{Rb} / \mathrm{Sr}$, dentre as 32 apresentadas inicialmente. As amostras foram dissolvidas em ácido perclórico e fluorídrico. Para as frações de Sr separadas em colunas de troca catiônica, foi usada uma resina Dowex 50W-X8. De maneira geral, foram seguidos os procedimentos descritos em Kawashita et al. (1974). Para métodos analíticos $\mathrm{K} / \mathrm{Ar}$, foram seguidos os procedimentos descritos em Amaral et al. (1966).

As constantes usadas para cálculos de idade foram:

$$
\begin{aligned}
& { }^{40} \mathrm{Ar} /{ }^{36} \mathrm{Ar}=295,5 \\
& \lambda \mathrm{e}(\mathrm{K})=0,581 \times 10^{-10} \mathrm{ano}^{-1} \\
& \lambda \mathrm{Rb}=1,42 \times 10^{-11} \mathrm{ano}^{-1}
\end{aligned}
$$

ESTRATIGRAFIA O Greenstone Belt de Goiás encontra-se inserido em rochas do Complexo Granito-Gnáissico e é estruturado, em termos gerais, segundo grandes sinformes e antiformes falhados. Estas dobras megascópicas apresentam eixos suborizontalizados, coincidentes com a direção geral de alongamento da faixa. Os contatos com o Complexo Granito-Gnáissico se dão através de falhas de empurrão N60$70 \mathrm{~W}$, responsáveis pelos limites grosseiramente retilíneos da faixa. A figura $1 \mathrm{~b}$ representa o mapa e a coluna geológica da porção sudeste da faixa.

Complexo Granito-Gnáissico O Complexo GranitoGnáissico é constituído por rochas de composição granodiorítica. Diques de rochas básicas, como metandesitos e metabasaltos, cortam o complexo, mas parecem não interseptar os litotipos do Greentone Belt de Goiás, sugerindo idade arqueana para aqueles.

Grupo Goiás Velho O Grupo Goiás Velho, também conhecido como Faixa Serra de Santa Rita (Danni 1988), representa o Greenstone Belt de Goiás, como foi definido inicialmente por Sabóia (1979) e Teixeira (1981). Pode ser dividido em três unidades: Unidade Ultrabásica Inferior, Unidade Básico-Intermediária e Unidade Metassedimentar Superior.

A Unidade Ultrabásica Inferior constitui a porção basal da seqüência e apresenta predominância em rochas metavulcânicas de natureza komatíítica, representadas por serpentinitos e talco xistos. Mostra textura spinifex, estruturas como pillow lavas e contém freqüentes intercalações de camadas de metachert ferrífero e filito grafitoso, sugerindo ambiente submarino para o vulcanismo.

A Unidade Básico-Intermediária é constituída por rochas metavulcânicas básicas, de natureza predominantemente toleítica, representadas por epídoto-quartzo-actinolita xisto (Subunidade A) e também por rochas piroclásticas de composição intermediária a ácida (Subunidade B), mostrando caráter cálcio-alcalino.

A Unidade Metassedimentar Superior é representada por rochas metassedimentares tais como: filito pelítico, filito 


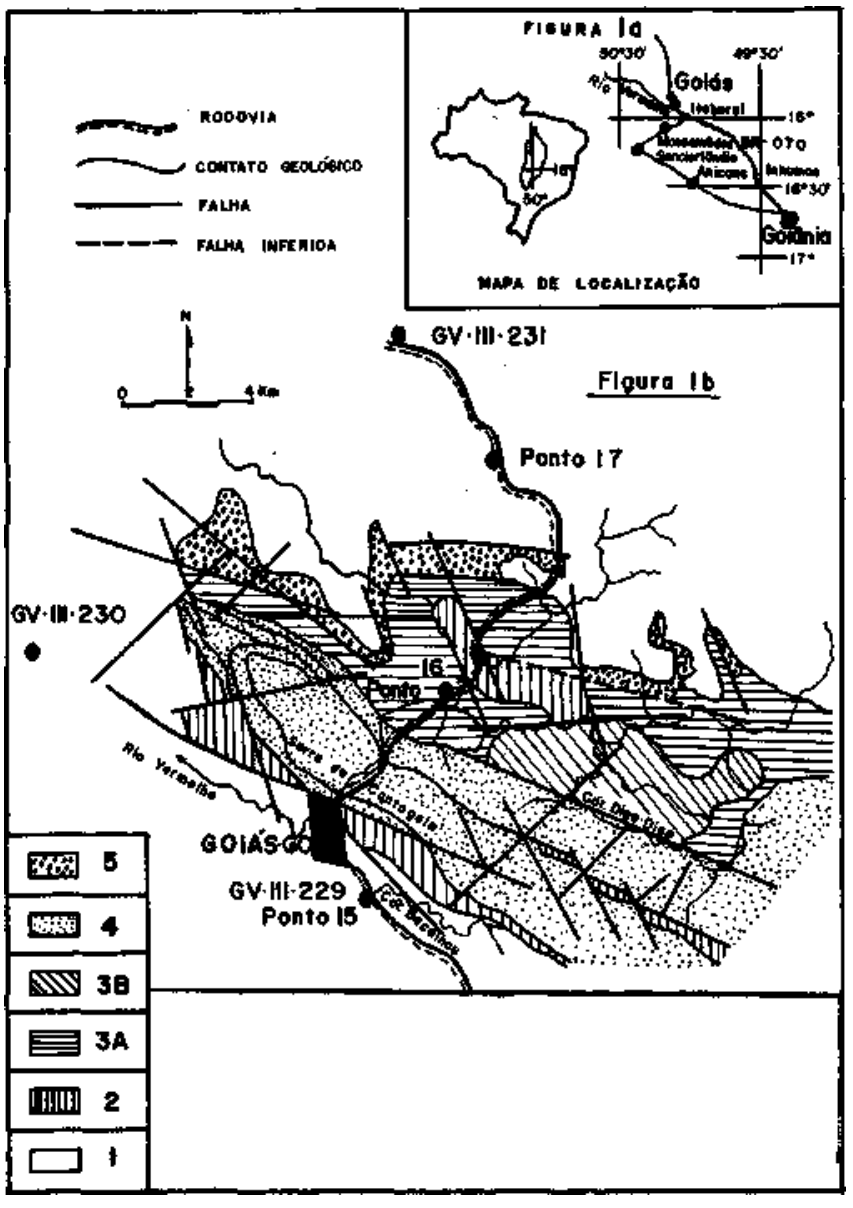

Figura Ia - Mapa de localização e acesso Figure l a - Local ization and access map

Figura Ib-Mapa geológico. 1. Complexo Granito-Gnáissico; 2. Unidade Ultrabásica Inferior; 3. Unidade BásicoIntermediária; 3a. Subunidade A; 3b. Subunidade B: 4. Unidade Metassedimentar Superior; 5. Grupo Araxá

Figure $1 \mathrm{~b}$ - Geologic map

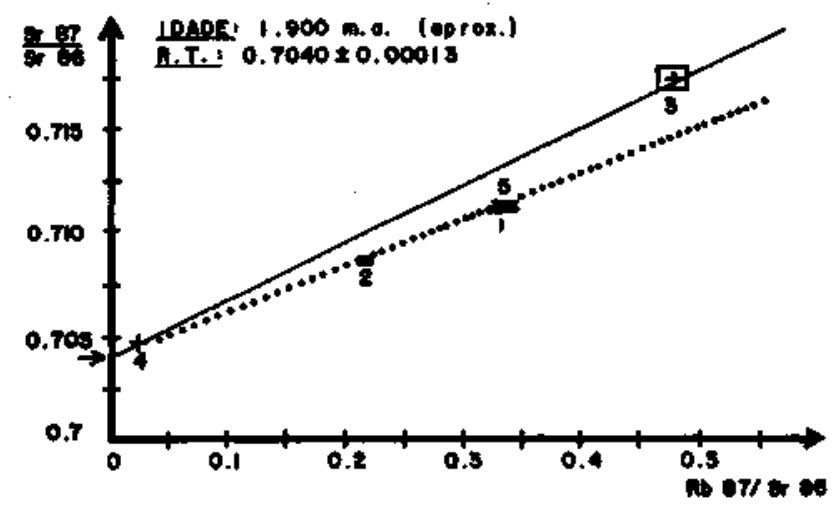

Figura 2 - Isócrona $\mathrm{Rb} / \mathrm{Sr}$ referente a hornblenda gnaisse do Corrego Bugre (GV-I I I -230)

Figure 2 - Rb/Sr isochrone of Bugre Creek hornblende gneiss (GV-III-230)

grafítoso e grafita xisto, com intercalações de lentes de metachert, formação ferrífera e hematita-dolomita mármore. É também constituída por metagrauvaca, sericita quartzito, serieita-quartzo xisto e metaortoconglomerado.

Maiores detalhes sobre a estratigrafia podem ser obtidos em
Danni et al. (1981), Tomazzoli (1981), Tomazzoli (1985), Tomazzoli et al. (1986).

TRABALHOS ANTERIORES SOBRE A GEOCRONOLOGIA As rochas que compõem o Complexo Granito-Gnáissico nos arredores do Greenstone Belt de Goiás são, na verdade, conhecidas em detalhes. Quanto aos aspectos geocronológicos, Hasui\& Almeida (1 970) realizaram datações radiométricas nesses gnaisses pelo método $\mathrm{K} / \mathrm{Ar}$, obtendo idades mínimas em torno de 1.200 Ma, possivelmente relacionadas ao evento tectono-termal Uruaçuano.

Gnaisses próximos à região de Goiás foram datados por Tassinari \& Montalvão (1980) e por Hasui et al. (1980) pelo método $\mathrm{Rb} / \mathrm{Sr}$, tendo sido determinadas idades em torno de $2.900 \mathrm{Ma}$.

Idades arqueanas foram também obtidas na região por Tassinari et al. (1981), que, utilizando idades isocrônicas $\mathrm{Rb} /$ $\mathrm{Sr}$, delimitaram tentativamente províncias geocronológicas no centro-oeste brasileiro.

AS ROCHAS DATADAS Os trabalhos geocronológicos consistiram na datação radiométrica dos gnaisses do Complexo Granito-Gnáissico, encaixantes ao Greenstone Belt, pelo método $\mathrm{Rb} / \mathrm{Sr}$ em rocha total. Foram também realizadas datações pelo método K/Ar sobre anfibólios de albita/quartzoactinolita xisto e de anfibólio metabasito, que representam, respectivamente, rocha vulcânica básica metamorfizada, integrante da Unidade Básico-Intermediária do Greenstone, e rocha básica de dique, inserida no Complexo GranitoGnáissico. O método $\mathrm{K} / \mathrm{Ar}$ também foi utilizado sobre moscovita, na datação de gnaisse cataclástico, que ocorre em contato tectônico com as rochas do Greenstone Belt.

Os afloramentos das rochas datadas são indicados no mapa geológico da figura $\mathrm{l} b$. A numeração destes pontos é referente ao das tabelas 1 e 2 .

AS DATAÇÕES Rb/Sr As datações $\mathrm{Rb} / \mathrm{Sr}$ em rocha total foram realizadas sobre hornblenda gnaisse (gnaisse Córrego Bugre - GV-III-230), muscovita-biotitagnaisse (GVI I I -231) e muscovita gnaisse (gnaisse cataclástico Córrego do Bacalhau - GV-III/229).

A tabela 1 mostra os resultados analíticos das datações $\mathrm{Rb} /$ Sr. Nela não são indicadas as idades de cada amostra pelo método convencional, já que estas são desprovidas de significado geológico em virtude das baixas razões $\mathrm{Rb} / \mathrm{Sr}$ apresentadas.

\section{HORBLENDA GNAISSE (GNAISSE CÓRREGO BUGRE)} As amostras do ponto GV-III-230 mostram um acentuado bandamento, marcado por bandas claras, quartzo-feldspáticas, alternadas com bandas escuras, com base de hornblenda e clorita. A textura dominante é a granoblástica, devido a predominância de quartzo, plagioclásio e microclínio. $\mathrm{O}$ anfibólio, em idioblastos prismáticos, é de ocorrência mais restrita e apresenta-se com tendência à orientação preferencial, sendo freqüentemente substituído por clorita. A maior parte das amostras coletadas neste ponto apresentou evidências de sericitização incipiente sobre os feldspatos, provavelmente pela alteração intempérica.

A figura 2 representa o diagrama isocrônico, a partir de amostras deste gnaisse, aflorante no leito do Córrego Bugre. Os cinco pontos do diagrama mostram um baixo alinhamento. A isócrona foi traçada levando-se em conta o fato de as amostras 1,2 e 5 apresentarem um grau de alteração intempérica pouco mais elevado.

$\mathrm{O}$ valor geocronológico obtido, de cerca de $1.900 \mathrm{Ma}$, parece representar uma idade mínima, devido à natureza dos terrenos datados e à comparação com as demais idades isocrônicas relatadas a seguir.

A razão inicial de 0,7040 parece refletir uma origem a partir da fusão parcial de rochas do manto ou de rochas siálicas recém incorporadas à crosta continental. 
Tabela 1 - Dados analiticos das datações $\mathrm{Rb} / \mathrm{Sr}$

Table 1 - Anal itic data of the $\mathrm{Rb} / \mathrm{Sr}$ method

\begin{tabular}{|c|c|c|c|c|c|c|}
\hline LITOTIPO & $\begin{array}{c}\mathrm{N}^{*} \mathrm{DA} \\
\mathrm{A} O \mathrm{OS} \text { T A }\end{array}$ & $N^{*} \quad D E \quad$ CAMPO & $\mathrm{Rb} \quad(\mathrm{ppm})$ & Sr $\quad(p \mathrm{pm})$ & R B & R $\left.b^{4}\right) s x^{*}$ \\
\hline $\begin{array}{l}\text { Hornblenda } \\
\text { Gatiss }\end{array}$ & $i$ & GV. [ I I - $230 \mathrm{a}$ & 54,1 & 478.1 & 0.324 & $0+7111$ \\
\hline $\begin{array}{l}\text { Hornblends } \\
\text { Onatige }\end{array}$ & 2 & $G V-111-230 b$ & 45,3 & 608,1 & 0.216 & 0,7085 \\
\hline $\begin{array}{l}\text { Hornblendy } \\
\text { Gaxise }\end{array}$ & 3 & $G v-111-230 \mathrm{c}$ & 57.7 & 313.9 & $0.4 d 7$ & 0,7175 \\
\hline $\begin{array}{l}\text { Hornblenda } \\
\text { Gatsog }\end{array}$ & 4 & $G Y-111-230 \mathrm{e}$ & 101.4 & 336.7 & 0.025 & 0,7047 \\
\hline $\begin{array}{l}\text { Hornblenda } \\
\text { Gnaisse } \\
\end{array}$ & 5 & $0 v-113.250 \mathrm{~h}$ & 48.9 & 422.8 & 0,335 & $0,7 \pm 13$ \\
\hline $\begin{array}{l}\text { Musc-Biotita } \\
\text { Onaisse }\end{array}$ & 6 & GV.111.2315 & 29,1 & 625,3 & 0.135 & 0,7075 \\
\hline $\begin{array}{l}\text { Mac-giolite } \\
\text { Oneige }\end{array}$ & 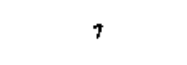 & GV-III-2]Id & 42,2 & 675,8 & 0.198 & 0.7098 \\
\hline $\begin{array}{l}\text { Musce-Biolite } \\
\text { Gndisse }\end{array}$ & 8 & $G V-J 11.231 \mathrm{~m}$ & 52,9 & 541,0 & 0.283 & 0,7127 \\
\hline $\begin{array}{l}\text { Musc-Bionita } \\
\text { Gnaisse }\end{array}$ & 9 & GV $-I I I-23 I h$ & 33.9 & 542,0 & 0,153 & 0,7066 \\
\hline $\begin{array}{l}\text { Muscostat } \\
\text { Onatsse }\end{array}$ & 11 & $G \mathrm{~V}-I 11-229 \mathrm{~b}$ & 78,7 & 220.6 & 1,037 & 0,7516 \\
\hline $\begin{array}{l}\text { Muscorita } \\
\text { Gutase }\end{array}$ & 12 & $0 V-t 11-229 c$ & 88,2 & 233,8 & 1,095 & 0,7413 \\
\hline $\begin{array}{l}\text { Mugcovite } \\
\text { Gatisse }\end{array}$ & 13 & $6 \mathrm{~V}-111 .-229 \mathrm{~d}$ & 45,3 & 259,7 & 0,506 & 0.7274 \\
\hline $\begin{array}{l}\text { Muscevite } \\
\text { Gnaisat }\end{array}$ & $1 \mathrm{~A}$ & $G V+111-2 \geq 9 \mathrm{e}$ & 3,4 & 224,5 & 0,509 & 0.7276 \\
\hline
\end{tabular}

Tabela 2 - Dados analiticos das dataçöes $K / A r$ Table 2 - Analytic data of the K/Ar method

\begin{tabular}{|c|c|c|c|c|}
\hline LETOTIPO & $\begin{array}{c}\mathrm{N}^{*} \mathrm{DA} \\
\text { ANOSTRA }\end{array}$ & $\begin{array}{l}N^{\circ} D E \\
\text { CAMPO }\end{array}$ & $\begin{array}{l}\text { MINERAL } \\
\text { ANALISADO }\end{array}$ & IDADE \\
\hline $\begin{array}{l}\text { Muscovita } \\
\text { Gnatsse }\end{array}$ & 15 & 6V-II]-229 & Muscovita & $1,471,4+-48,3 \mathrm{Ma}$ \\
\hline $\begin{array}{l}\text { Actinolìta } \\
\text { Xisto }\end{array}$ & 16 & GV-L-23 & Aclinglita & $1.274,5+-32,9 \mathrm{Ma}$ \\
\hline $\begin{array}{l}\text { Anfibólio } \\
\text { Metabasito } \\
\text { (de dique) }\end{array}$ & 17 & GV-1H-50h & Aclinolita & 1. $339,2+-49,0 \mathrm{Ma}$ \\
\hline
\end{tabular}

O ponto 4 da isócrona, por estar próximo à coordenada do gráfico, é bom controlador da razão inicial, conferindo uma boa precisão a este valor, como mostram Vlach \& Cordani (1986).

MUSCOVITA-BIOTITA GNAISSE (GV-III-231) Amostras deste litotipo foram obtidas em pedreira à margem da rodovia Goiás-Aruanã, a cerca de $20 \mathrm{~km}$ da cidade de Goiás.

Mostram textura granoblástica, de granulação média, dada pela predominância de quartzo e feldspato. Os minerais filitosos, como muscovita e biotita, mesmo sendo pouco abundantes, tendem a desenvolver finas e escassas bandas orientadas segundo direção preferencial. Os feldspatos apresentam geralmente formas amebóides, xenoblásticas. O plagioclásio possui leve tendência porfiroblástica e muitas vezes aparece englobando ou reagindo com o microclínio. A biotita está muitas vezes intercrescida com a muscovita nas bandas filitosas. As amostras apresentam incipiente sericitização e epidotização sobre os feldspatos.

A figura 3 representa o diagrama isocrônico deste litotipo, no qual os pontos 6,7 e 8 apresentam bom alinhamento, ao contrário do ponto 9 , que parece representar amostra não-

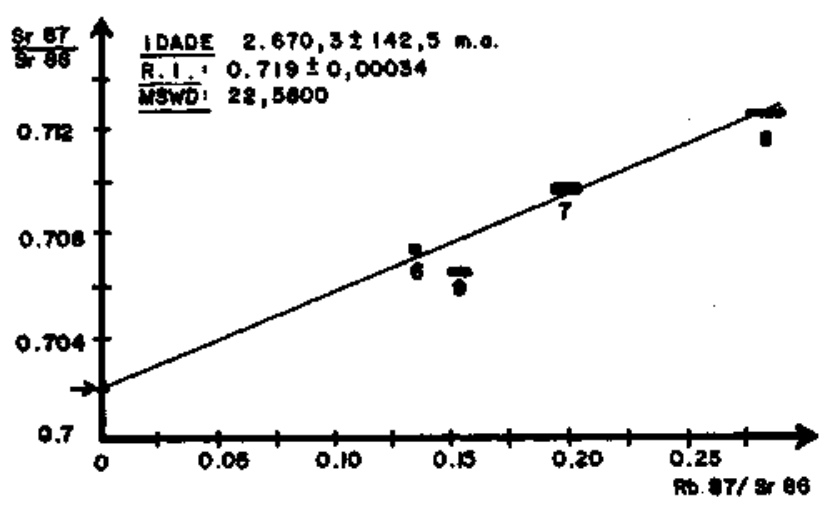

Figura 3 - Isócrona $\mathrm{Rb} / \mathrm{Sr}$ referente à muscovita-biotita gnaisse (GV-III -231)

Figure $3-\mathrm{Rb} / \mathrm{Sr}$ isochrone of muscovite-biotite gneiss (GV-III-231)

cogenética, já que o grau de alteração destas é mínimo.

A idade obtida pela isócrona é de $2.670,3 \pm 142 \mathrm{Ma}$. Arazão inicial de 0,7019 é baixa e sugere origem a partir de fusão parcial de material de manto.

MUSCOVITA GNAISSE (gnaisse catadas tico do Córrego Bacalhau) As amostras do ponto GV-III-229 apresentam evidentes aspectos cataclásticos, mostrados por porfiroblastos relícticos de plagioclásio, completamente sericitizados e epidotizados, sobre uma matriz cataclástica mais fina, recristalizada, com base de quartzo, microclínio e plagioclásio, mostrando seções límpidas, isentas de sericitização. Mostram-se, freqüentemente, com junções tríplices a $120^{\circ} \mathrm{e}$, ao contrário dos feldspatos rei ícticos, são minerais neoformados por metamorfismo cataclástico, fácies anfibolito baixa, que afetou estas rochas de alto grau. A muscovita ocorre em lamelas de até $5 \mathrm{~mm}$, com tendência 


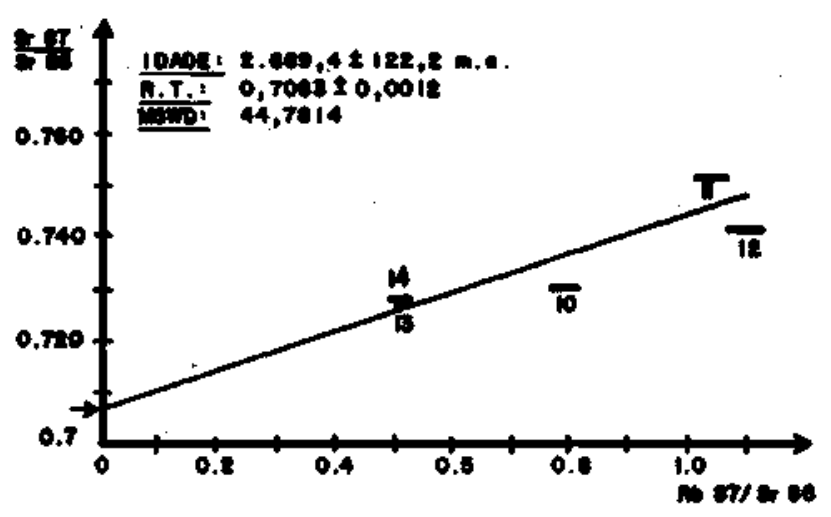

Figura 4 - Isócrona $\mathrm{Rb} / \mathrm{Sr}$ referente à muscovita gnaisse cataclástico do Córrego Bacalhau (GV-III-229)

Figure 4 - Rb/Sr isochrone of Bacalhau Creek muscovite cataclastic gneiss (G V$111-229)$

a formar finas bandas que contornam pré-tectonicamente os porfiroblastos serieitizados de feldspato relíctico. Parece ter sido recristalizada durante o metamorfismo cataclástico.

A figura 4 representa o diagrama isocrônico das amostras referentes a este litotipo. Como os pontos do diagrama apresentam grande dispersão, a isócrona obtida representa uma reta média, de referência. Esta isócrona indica idade de $2.669,6 \pm 122,2$ Ma e razão inicial relativamente elevada, em torno de 0,7063 , que aponta para derivação a partir da fusão de rochas siálicas, recém incorporadas à crosta continental.

AS DATAÇÕES K/Ar Os dados analíticos das datações $\mathrm{K} /$ Ar são apresentados na tabela 2. Foram analisados, por este método, muscovita gnaisse (o mesmo gnaisse cataclástico do Córrego Bacalhau), albita/quartzo-actinolita xisto e anfibólio metabasito (rocha de dique).

MUSCO VITA GNAISSE (gnaisse cataclástico Córrego Bacalhau) Esta rocha (GV-III-229) é a mesma datada pelo método $\mathrm{Rb} / \mathrm{Sr}$, quando então revelou idade arqueana. A datação $\mathrm{K} / \mathrm{Ar}$, realizada sobre muscovita, mostrou, no entanto, idade de $1.471 \pm 48,3 \mathrm{Ma}$.

A muscovita analisada é mineral recristalizado durante o processo de metamorfismo cataclástico que afetou os gnaisses na região de contanto com o Greenstone Belt, visto que este contato se dá através de falhas de empurrão, direcionadas segundo direção N70W.

Portanto, a idade obtida está relacionada à geração dos falhamentos ou, pelo menos, a processos de reativação posterior destes.

ALBITA-QUARTZO-ACTINOLITA XISTO Este litotipo, aflorante no ponto 16 do mapa geológico da figura $1 \mathrm{~b}$, representa rocha vulcânica básica da Unidade Básico-Intermediária do Greenstone Belt de Goiás, metamorfizada no grau baixo, fácies xisto verde.

Apresenta microporfiroblastos de actinolita (em média, 1 $\mathrm{mm}$ ), orientados e definindo foliação sobre matriz de granulação mais fina, com base de quartzo, albita e actinolita. Os processos de substituição parcial da actinolita pela clorita e epidotização incipiente da albita indicam estágio inicial de alteração intempérica.

A datação K/Ar em actinolita revelou idade de $1.274,5 \pm$ $32 \mathrm{Ma}$, provavelmente idade mínima relacionada ao processo de difusão do argônio ocorrido durante a atuação do evento tectono-termal uruaçuano.

ANFIBÓLIO METABASITO Representa um dique de rocha ígnea básica, inserido em rochas do Complexo Granito-
Gnáissico, metamorfizado na fácies xisto verde (ponto 17 do mapa da Fig. 1 b).

Mostra cor verde, granulação média e estrutura foliada, conferida pela orientação preferencial de anfibólio. Seus constitutivos são: anfibólio (actinolita), minerais opacos (magnetita), clorita, quartzo, albita, epídoto, titanita, em ordem decrescente de abundância relativa. A clorita tende a substituir parcialmente o anfibólio e também a formar finas bandas contínuas nas quais são freqüentes os microidioblastos octaédricos de magnetita.

A datação $\mathrm{K} / \mathrm{Ar}$, realizada em actinolita, acusou idade de $1.839,2 \pm 49,0 \mathrm{Ma}$, provavelmente relacionada ao evento tectono-termal transamazônico.

É importante ressaltar que a actinolita datada é mineral metamórfico e, portanto, a idade obtida é relativa ao metamorfismo que afetou a rocha ígnea, de idade mais antiga.

CONSIDERAÇÕES FINAIS Nas datações geocronológicas realizadas foram utilizados os métodos $\mathrm{K} / \mathrm{Ar}$ e $\mathrm{Rb} / \mathrm{Sr}$. As rochas datadas foram os gnaisses encaixantes e as rochas metavulcânicas do Greenstone Belt, bem como amostra de dique básico, inserido em rochas do Complexo GranitoGnáissico.

Há, sem dúvida, uma grande limitação destes métodos em terrenos polimetamórficos por causa da dispersão do Ar e aos rejuvenescimentos isotópicos $\mathrm{Rb} / \mathrm{Sr}$ provocados pelos diversos fenômenos geológicos de natureza termal e tectônica que, de modo geral, posicionam-se segundo idades mais ou menos bem definidas.

Os terrenos estudados mostraram idades arqueanas em gnaisses amostrados nos pontos GV/III/229 (Córrego do Bacalhau) e GV-III-231 (Fig. 1 b), apresentando, respectivamente, idades de 2.669,4 Ma e 2.670,3 Ma.

Datações em outros pontos e por outros métodos (como foi 0caso do gnaisse do Córrego Bacalhau, datado também pelo método K/Ar) revelaram idades mais recentes, como resultado de reativações tectono-termais posteriores.

A variedade de litotipos datados e a utilização de dois métodos de determinação de idade radiométrica conjugados, aliados a um controle geológico de grande detalhe, tornam os resultados obtidos de grande significação geológica.

$A$ isócrona traçada na figura 4 , referente ao gnaisse aflorante no Córrego Bacalhau (GV-III-229), apesar de ser uma reta média entre pontos pouco alinhados, apresenta idade de $2.669,4 \pm 122,2 \mathrm{Ma}$, compatível com a natureza geológica da região estudada.

Por outro lado, os pontos do diagrama da figura 3, referentes ao muscovita-biotita gnaisse do ponto GV-III-231, mostramse melhor alinhados e confirmam idade isocrônica arqueana de 2.670,3 $\pm 142,5 \mathrm{Ma}$.

O hornblenda gnaisse do Córrego Bugre, representado pelo diagrama isocrônico da figura 2 , mostrou idade em torno de

1.900 Ma, possivelmente relacionada ao evento termo-tectônico transamazônico que teria provocado homogeneização isotópica nas amostras.

Datação K/Ar em muscovita sobre o muscovita gnaisse cataclástico do Córrego Bacalhau (GV-III-229), datado também pelo método $\mathrm{Rb} / \mathrm{Sr}$, revelou idade de $1.471,4 \pm 48,3 \mathrm{Ma}$ para o evento de metamorfismo cataclástico que afetou este litotipo arqueano. Este processo deve estar relacionado com reativações das falhas de empurrão direcionadas segundo N70 W e que perfazem os contatos do Greenstone Belt com as rochas gnáissicas.

Os diques de rochas básicas inseridas no Complexo Granito-Gnáissico são representados pela amostra GV-II-50b (anfibólio metabasito), cuja datação K/Ar sobre actinolita metamórfica mostrou idade de 1.839,2 \pm 49 Ma. Esta idade transamazônica é mínima, pois deve significar, pelo menos, a idade do metamorfismo que afetou a rocha ígnea, mais antiga. 
$\mathrm{O}$ fato destes diques aparentemente não seccionarem o Greenstone Belt levou Danni et al. (1981) a sugerirem um posicionamento estratigráfico contemporâneo relacionado ao Arqueano entre os diques e as rochas do Greenstone Belt. No entanto, cabe ponderar que a maior parte dos contatos da faixa se dá através de falhamentos que comprovadamente tiveram reativações posteriores. Estas reativações, que levaram ao contato direto das rochas do Grupo Araxá com as do Greenstone Belt, poderiam também ser responsáveis pelo truncamento de diques não necessariamente arqueanos no contato com a faixa.
Datacão K/Ar sobre actinolita de rocha metavulcânica básica do Greenstone Belt (actinolita xisto GV-I-23) revelou idade de $1.274,5 \pm 32,9 \mathrm{Ma}$, provavelmente relacionada a reflexo do evento tectono-termal uruaçuano sobre a seqüência.

Agradecimentos $\mathrm{O}$ autor expressa agradecimentos à equipe do Centro de Pesquisas Geocronológicas da USP pela realização das análises, ao prof. Márcio M. Pimentel pelas sugestões oportunas e ao Conselho Nacional de Desenvolvimento Científico e Tecnológico $(\mathrm{CNPq})$ pelo apoio financeiro durante a execução do projeto.

\section{REFERÊNCIAS BIBLIOGRÁFICAS}

ALMEIDA, F.F.M. 1968. Evolução tectônicado centro-oeste brasileiro. An. Acad. bras. Ciên.,40:(Supl.):285-295.

AMARAL, G.; CORDANI, U.G.; KAWASHITA, K.; REYNOLDS, J.H. 1966. Potassium-argon dates of basaltic rocks from Southern Brazil. Geochim Cosmochim Acta, 30:159-189.

DANNI, J.C.M.; DARDENNE, M.A.; FUCK, R.A. 1981. Geologiada região de Goiás (GO): O Greenstone Belt da Serra de Santa Rita e a Seqüência Serra do Cantagalo. In: SIMP. GEOL. CENTRO-OESTE, 1. Goiânia, 1981. Atas... Goiânia, SBG. p. 265-280.

DANNI, J.C.M. 1988. Os Greenstone Belts da Província Tocantins no Estado de Goiás, Brasil. Rev. Bras. Geoc., 18(4):381-390.

HASUI, Y. \& ALMEIDA, F.F.M. 1970. Geocronologia do centro-oeste brasileiro. Boi. $S B G, 19(1): 7-26$.

HASUI, Y: TASSINARI, C.C.G.; SIGA, O., Jr; TEIXEIRA, W; ALMEIDA, F.F.M.;KAWASHITA,F.1980.DataçõesRb/SreK/Arnocentro-oestedo Brasil e seusignificadogeológico-getectônico. In: CONOR. BRAS. GEOL., 31. Camboriu, 1980. Anais... Camboriu, SBG. v. 5, p. 2659-2678.

KAWASHITA,K.;MANTOVANI,M.;THOMAZ,A.,F';TORQUATO,J.; BERENHOLE, M. 1974. Procedimentos das Análises do Centro de Pesquisas Geocronológicas da USP. São Paulo, CPG - USP. (Relatório Interno).

SABÓIA, C.A. 1979. Os Greenstone Belts de Crixás e Goiás. Boi. Inf. SBG $N C O, 9: 43-72$.

TASSINARI, C.C.G. \& MONTALVÃO, R.G.M. 1980. Estudos geocronológicos do Greenstone \&?//deCrixás. In: CONGR. BRÁS. GEOL.,31. Camboriu, 1980. Anais... Camboriu, SBG. v. 5, p. 2759.
TASSINARI, C.C.G.; SIGA, O., Jr.; TEIXEIRA, W. 1981. Panorama geocronológico do centro-oeste brasileiro. In: SIMP. GEOL. CENTROOESTE, 1. Goiânia, 1981. Atas... Goiânia, SBG. p. 93-116.

TEIXEIRA, A.S. 1981. GeologiadaregiãodeGoiás-Faina. In: SIMP. GEOL. CENTRO-OESTE, 1.Goiânia, 19\% Atas Goiânia SBG p.344-360.

TOMAZZOLI, E.R. 1985. Geologia, Petrologia, Deformação e Potencial AuriferodoGreenslone Beltofe Goiás (GO). Brasil ia. 206 p. (Dissertação de Mestrado, IG/UnB).

TOMAZZOLI, E.R \& NILSON, A. A. 1986. Contribuição à geologia, metamorfismo e deformação do Greenstone Belt ás Goiás (GO). In: CONGR BRÁS. GEOL., 34. Goiânia, 1986. Anais... Goiânia, SBG/NCO. v. 2, p. 615-629.

TOMAZZOLI, E.R.; NILSON, A.A.; SANTOS, M.M.; TEIXEIRA, A.S 1986. Geologia da região de Americano do Brasil - cidade de Goiás. In: CONGR. BRÁS. GEOL., 34. Goiânia, 1986. Roteiros... Goiânia, SBG. boi. 2, p. $95-130$.

TOMAZZOLI, E.R. 1991. Texturas spinifex das rochas magnesianas do Greenstone Belt deGoiás(GO). In: SIMP. GEOL. CENTRO-OESTE, 3. Cuiabá, 199|.Atas... Cuiabá,SBG. p. 175-184.

VLACH, S.R.F. \& CORDANI, U.G. 1986. A sistemática $\mathrm{Rb} / \mathrm{Sr}$ em rochas granitóides. Rev. Bras. Geoc., 16(1):38-54.

MANUSCRITOA646

Recebido em 9 de marco de 1990 Revisão do autor em 30 de setembro de 1991 Revisão aceita em 22 de outubro de 1991 